\title{
Comparative effect of micro needling and its impact on training in water during the treatment of women with varicose legs
}

\author{
Vahideh Riyahi', Bijan Goodarzi ${ }^{2}$, Vahid Riyahi ${ }^{3}$ and Fatemeh Mohamadpour Vahedi ${ }^{4}$ \\ ${ }^{1}$ Master in Physical Education, Minister of Education, Maragheh, Iran \\ ${ }^{2}$ Assisstant Professor, Department of Physical Education and Sports Sciences, Borujerd Branch, Islamic Azad \\ University, Borujerd, Iran \\ ${ }^{3}$ Master in Physical Education, Minister of Education, Maragheh, Iran \\ ${ }^{4}$ Director Ministry of Education, Maragheh, Iran
}

\begin{abstract}
The present study aims to compare the effect of a period of micro needling and impact of training in water in the treatment of women with varicose legs. For this purpose, 30 women were selected as subjects with varicose veins of the lower limb. After randomization of subjects into three groups of 10 people, for 20 weeks, a meeting every 4 weeks and a total of 5 sessions using micro needling and training in water was conducted on patients. The control group did not have any therapeutic interventions. To analyze the data, paired and independent t-test were used at a significance level of 05/0> P. The findings have shown that among the measured values the improvement index before and after the test for micro needling significantly increases and decreases respectively 05/0> P. The results showed that the use of micro needling can be used as a safe and effective treatment in people with varicose veins of the lower body. The study showed a 76 percent reduction in the size of the ankle after a week of treatment of the groups receiving training in water.
\end{abstract}

KEY WORDS: VARICOSE VEINS, MICRO NEEDLING, HORSE CHESTNUT

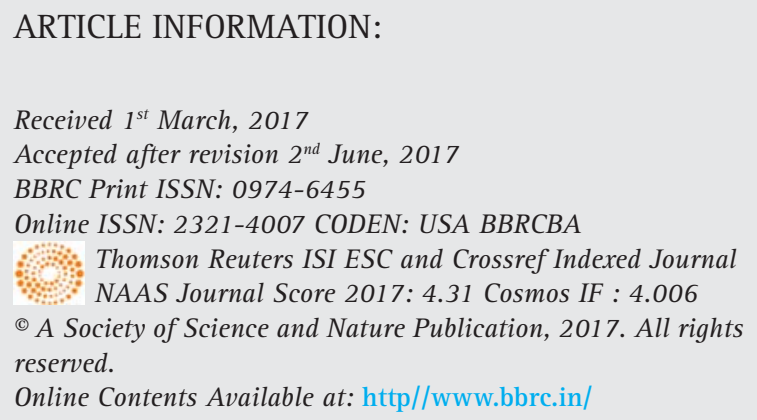




\section{INTRODUCTION}

Varicose veins originating from the Latin root Varix means twisted, and it refers to swollen vein or dilate veins. Varicose veins, is the most common human vascular disease that affects about 10-20\% of the population. Varicose veins are veins long, dilated and twisted and is often seen at the interior surfaces of the lower limbs. The highest prevalence of varicose veins is estimated among women aged 40-49 years. Varicose veins are large, fully bulged and noticeable and sometimes palpable and dilated and elongated, and sometimes have more than $4 \mathrm{~mm}$ diameter. Swollen and spider web-like Varicose veins are very common (Harrie \&t Kendall, 2014).

More than 40 percent of women over 50 suffer from the disease. Varicose veins are superficial veins, dilated and zigzagged due to structural defects and performance of the saphenous veins, or due to the inherent weakness of the vein wall or rarely due to Arteriovenous fistulas. More than 20 million adult Americans are suffering from varicose vein disease. The disease causes a feeling of illness or nausea and as a result reduces the normal functions of the patient. These veins are related to leg swelling, pain, dermatitis, phlebitis and ulcers. Patients with venous failure often complain of pain in their legs that worsen with prolonged standing and is relieved by elevating the feet. In the examination of shank diameter, edema of superficial varicose veins and erythema, dermatitis, hyperpigmentation can be seen in the lower leg and the skin near the external ankle might become ulcerous .Varicose veins are mostly asymptomatic and only the aesthetic aspects require medical attention. If symptomatic, the pain, fullness and diffused non-specific heaviness are felt in the legs, especially after standing a long time. Sometimes swelling in the ankles and bulged vessels can be seen in the feet (Chung et al., 2000 Harrie \& Kendall, 2014).

Avoiding long time standing or sitting position, avoiding long-time exposure of legs in the sun and heat or prolonged contact with garter or belt, avoidance of continuous wearing of strip (band) or stockings, avoiding simple sugars and lipids and the use of medications such as flavonoid derivatives, sodium morrhuate are among the methods of reducing the symptoms of varicose veins(Stiegmann, Sun, \& Hammond, 1988) .

Microneedling is a method recently used for skin diseases. Microneedling is a device for general skin needling which has a comparable impact with laser treatments and chemical peelings. This device can be used exclusively or as a complement to other treatment methods. . The disposable needles' points are short and tiny, it includes 12 microneedles that should be discarded after each treatment. For treatment, needle penetration depth must be between $25 \%$ to $2 / 5 \mathrm{~mm}$ set with a speed of
25 beats per second and beat for 90 beats per seconds which finally between 300 and 1,000 tiny holes in seconds are created in the surface. Microneedling is used to stimulate the skin to make natural collagen, (Harrie \& Kendall, 2014).

Furthermore, treatment with this device helps penetration and absorption of drugs to the skin, skin rejuvenation and wrinkles, acne scars healing, improvement of body craze and the overall appearance of the skin and shrinkage of the size of the pores. Backlog and increasing the elasticity of the skin, new collagen production, surface and deep wrinkles reduction, improving crazes, and improving decrements of pigmented lesions' peneteration ,materials, creams and vitamins to the skin after treatment with microneedling can be named as the advantages of microneedling (Van Stiegmann \& Goff, 1988)

Research has shown that many patients with varicose veins can control their disease through regular exercise, excess weight loss, self-care behavior, and drug control. In this regard, since the use of drugs in most cases is expensive, invasive, and associated with many side effects, physical activity must be considered as the focus of prevention and management of disease(Carr, 2006). Regular exercise stimulates blood circulation, improves the muscles power, and helps prevent varicose veins. On the other hand, intense aerobic activity, running, cycling, or any other strenuous activity may lead to increased blood pressure in the legs and intensify varicose veins (Gloviczki \& Yao 2001 and Goldman, 2002).

Hence, one of the ways that can lead to this type of activity is activity in water. Varicose veins are caused when the blood accumulates in the veins and blood flow is impaired. Aquatic exercise stimulates blood flow and reduces swelling veins. Soft pressure of water helps the blood move in the veins, and touch receptors located in the skin reduce irritation and sensitivity to pain(Diehm \& Diehm, 2002). Water buoyancy reduces the weight thus provides easy mobility in water for motor impaired people. Moreover, water resistance properties can create a form of resistance training conditions, which in addition to the physical benefits can create emotional benefits (Yaser \&t Sadeghi 2012).

In addition, water can also increase the flexibility of muscles and bones, thereby reducing muscle-bone spasms and increase the individual's power.Water exercise also reduces heart rate, cardiac workload and oxygen consumption during exercise on land(Ghaffari et al., 2008). In this regard, the results of the study by Ernst et al. (1992) where the impact of hot and cold water bath in 122 patients with varicose veins was examined, it was shown that the experimental group compared to the control group in the variables of muscle contraction, itching, pain when standing or sitting and sensitivity, 
showed significant improvement (Ernst et al., 1992). In the study by Mancini et al. (2003), the effect of a sulfur bath with hot water on the quality of life of patients with varicose veins revealed that the quality of life in these patients has significantly improved (Mancini Jr et al., 2003).

Given that the risk of varicose veins has become prevalent among the population, most of these patients would like to use non-invasive and non-pharmacological methods for treatment. Considering that few studies exist in the field of the impact of exercise on varicose, and so far, the theory of the efficiency of practice in water to improve varicose veins is based more on experience. Moreover, with respect to the role of self-control and non-pharmacological methods, such as sports activities, particularly water training, on the quality of life in patients with varicose, the aim of this study is to compare the effect of a period of micro needling and the impact of training in water on the treatment of women with foot varicose. A 20-week period of microneedling has no significant effect on the treatment of women with varicose leg. A 20-week period of training in water usage has no significant effect on the treatment of the women suffering from varicose legs.

\section{MATERIAL AND METHODS}

The study population included all women with varicose veins in the age range between 40 to 60 years who have gone to health centers for treatment.

The sample consisted of a total of 30 diagnosed women, of those, 10 patients were randomly divided into a control group and two groups of 10 people will be selected as the experimental group.After introducing the participants about the purpose of the study, in the first step, measuring pain intensity was performed using questionnaires. After the initial evaluation of samples, microneedling and training in water were used and conducted for 20 weeks and every four weeks for a total of 5 session meetings under the supervision of an expert. It should be noted that the research subjects must not have experienced the microneedling or the training in water, previously. Moreover, the use of any antidepressant medications during the study will be prohibited and any treatment with these drugs should be avoided for at least 7 days before the study begins. This study regarding the lack of any physical and psychological risks to the subjects was approved by sports medicine and orthopedic specialists.Subjects who were 30 patients were divided randomly into three groups equally. Group A: control group, including subjects who during the 20 -week study did not have any therapeutic intervention. Group B and $\mathrm{C}$, the experimental group who used microneedling and training in water for 20 weeks and a session for each 4 weeks and a total of 5 sessions.

In the present study to determine effects of microneedling and the training in water in two stages, mentioned indicators were measured regarding micro needling and the training in water: one day before the beginning, and in the second phase one day after the 20-week period ends.

The subjects had to answer questions based on a Likert scale of 5 options. Each subscale separately and based on visual analog scale VAS were qualitatively determined.

\section{RESULTS AND DISCUSSION}

\section{SURVEYING NORMAL DATA DISTRIBUTION IN MICRONEEDLING METHOD}

To study the normal distribution of data KolmogorovSmirnov test was used. According to this test, distribution is normal when the amount is significantly higher than 0/05. The results are provided in table (1-4).

Based on the results of Kolmogorov-Smirnov test, distribution data for all studied variables were normal. Therefore, statistical parametric tests were used for data analysis and hypothesis testing.

A 20-week period microneedling has no significant effect on improvement of women with skin-deep varicose legs.

To check this hypothesis, first and foremost, the statistical paired t-test (paired) were used to compare pretest and post-test of each group (Table 2-4) and then

\begin{tabular}{|c|c|c|c|c|}
\hline $\begin{array}{l}\text { The significance } \\
\text { level }\end{array}$ & $\begin{array}{l}\text { Average and } \\
\text { Standard deviation }\end{array}$ & Group & & Variables \\
\hline $44 / 0$ & $3 / 7 \pm 4 / 20$ & pre-Test & \multirow[t]{2}{*}{ Control } & \multirow{4}{*}{ Improvement } \\
\hline $31 / 0$ & $2 / 6 \pm 2 / 21$ & Post-Test & & \\
\hline $54 / 0$ & $2 / 3 \pm 1 / 19$ & Pre-Test & \multirow[t]{2}{*}{ Experimental } & \\
\hline $21 / 0$ & $5 / 8 \pm 5 / 12$ & Post-Test & & \\
\hline
\end{tabular}




\begin{tabular}{|c|c|c|c|c|c|c|c|}
\hline $\begin{array}{l}\text { The significance } \\
\text { level }\end{array}$ & $\mathrm{T}$ & $\begin{array}{l}\text { Degrees of } \\
\text { freedom }\end{array}$ & $\begin{array}{l}\text { Within-group } \\
\text { mean difference }\end{array}$ & Post-Test & Pre-Test & Group & Variable \\
\hline $089 / 0$ & $72 / 1$ & 9 & $3 / 1$ & $2 / 6 \pm 2 / 21$ & $3 / 7 \pm 4 / 20$ & Control & \multirow{2}{*}{ Improvement } \\
\hline $001 / 0$ & $11 / 7$ & 9 & $4 / 7$ & $5 / 8 \pm 5 / 12$ & $2 / 3 \pm 1 / 19$ & Experimental & \\
\hline
\end{tabular}

\begin{tabular}{|l|l|l|l|l|}
\hline \multicolumn{2}{|l|}{ Table 4-4. independent t-test results in post-test } \\
$\begin{array}{l}\text { Two-tailed } \\
\text { significance level }\end{array}$ & $\mathrm{t}$ & $\begin{array}{l}\text { Degrees of } \\
\text { freedom }\end{array}$ & $\begin{array}{l}\text { The mean difference } \\
\text { between groups }\end{array}$ & Variable \\
\hline $001 / 0$ & $2 / 5$ & 19 & $3 / 9$ & Improvement \\
\hline
\end{tabular}

\begin{tabular}{|c|c|c|c|c|}
\hline \multicolumn{5}{|l|}{ (Table 1) } \\
\hline \multirow[t]{2}{*}{ Variables } & \multirow[t]{2}{*}{ Groups } & \multirow{2}{*}{$\begin{array}{l}\text { Pre and post-test } \\
\text { difference }\end{array}$} & \multicolumn{2}{|c|}{ In-group comparison } \\
\hline & & & $t$ value & $+\mathrm{P}$ value \\
\hline Pain intensity & Exercise in water & $3.150 \pm 1.663$ & \multirow[t]{2}{*}{7.128} & \multirow[t]{2}{*}{$0.000+$} \\
\hline$(0-5)$ & Control & $0.300 \pm 0.656$ & & \\
\hline Life quality & Exercise in water & $-20.318 \pm 11.064$ & -6.889 & $0.000+$ \\
\hline$(0-100)$ & Control & $-2.920 \pm 2.265$ & & \\
\hline
\end{tabular}

t-test was used for comparison of independent groups (Table 2-4) at the significant level of P $\leq .0$ / 05.

Results showed that the experimental group in posttest after the exercise protocol in comparison to the pretest, show significant difference in the pain, and pain in the experimental group were significantly reduced. But in the control group no significant difference was observed in the degree of pain in the pretest and posttest. Also according to the results from the table, in comparing the change in the groups in post-test, significant difference was observed between the changes. Therefore, the null hypothesis of no effect of 20 weeks of microneedling on the improvement of the women suffering from skin-deep varicose leg is rejected and it can be stated that this type of intervention causes improvement in these individuals.

The results of data analysis within groups showed that after four weeks of training in the water, varicose veins improvement in the training group in water in post-test compared to pre-test was significantly different ( $p>0.05)$. However, in control group, only changes in improving quality of life were significant. In addition, comparing these variables showed significant differences in pain intensity and quality of life between the two groups ( $p>0.05)$.

The mean change in pain intensity and quality of life in the pre-test and post-test in control group and experi- mental group of exercise in water is also shown in the diagram (Figure 1, 2).

The results showed that four weeks of training in the water has a positive impact on reducing pain in women with varicose veins.

The results of this study are in line with the findings of Ernst et al. (1992) showing that exercise program results in a significant reduction in intensity of

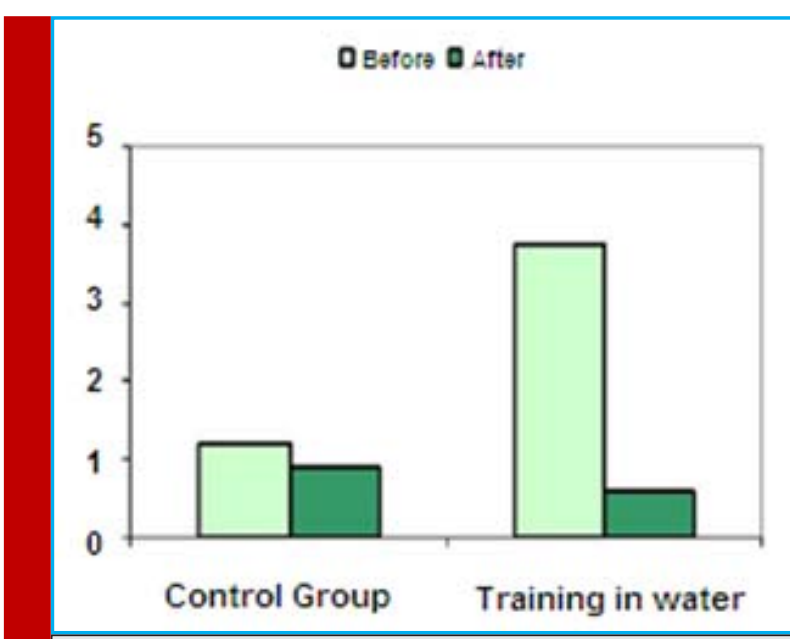

FIGURE 1. Comparing the changes in pain in pre-test and post-test in control and experimental groups. 


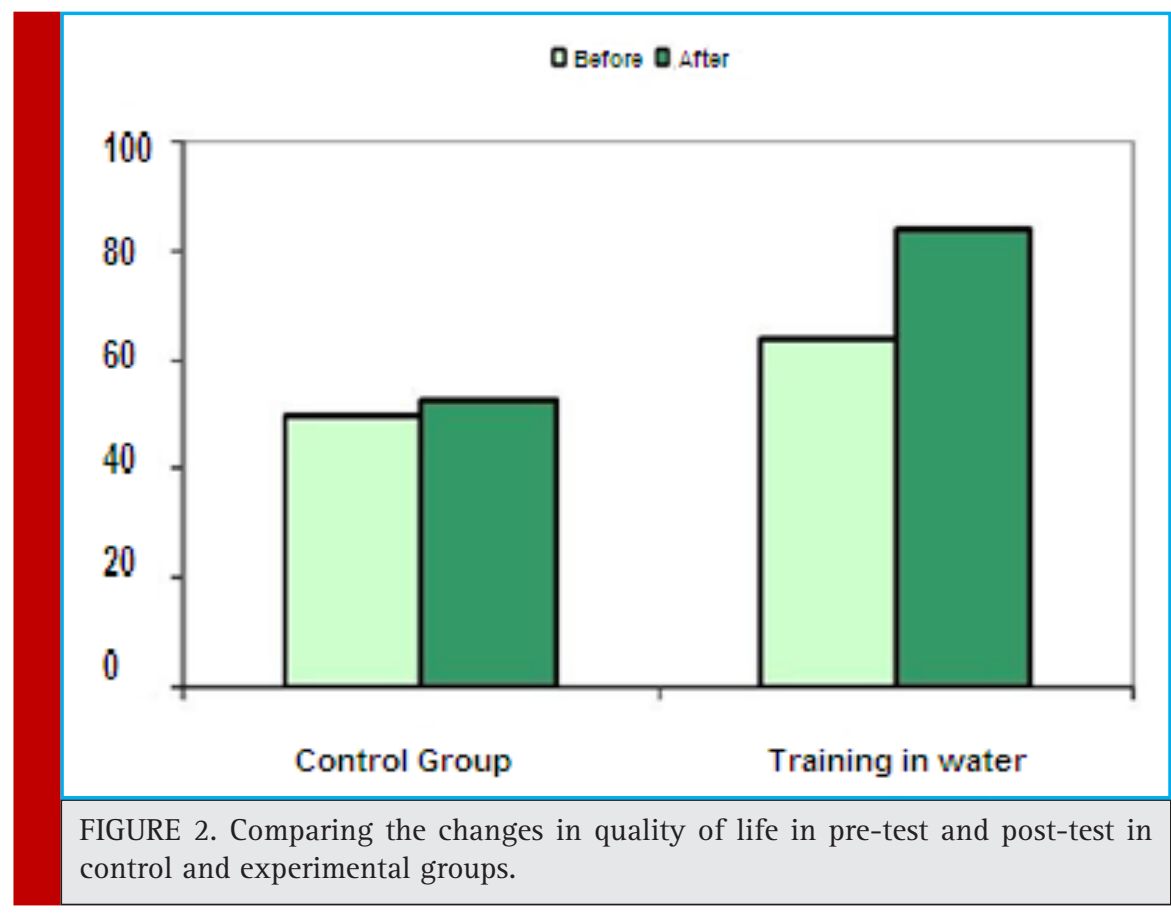

pain(Ernst et al., 1992). Although the method of Ernest et al. was different from that of ours and they used cold and hot water method, similar results were obtained; probably this could represent a desirable therapeutic property of water. Moreover, the findings of the present study demonstrate the efficacy of water exercise in improving the quality of life in patients with varicose veins, so that comparisons between groups showed that the average quality of life score between the two groups was significantly different $(\mathrm{p}<0.05)$. This finding was consistent with the findings of Mancini et al. (2003). In their study, they reported that a period of hot sulfur water bath could have positive effects on the quality of life in patients with varicose veins(Mancini Jr et al., 2003).

As aquatic exercise reduces the pressure load on joints and provides a suitable environment for activity of people, it can be very flexible, convenient, and delightful. Since many studies have shown a positive relationship between physical activity and mental health have shown, exercises in water can be a step towards enhancing the quality of life of people with varicose veins .

\section{CONCLUSION}

Microneedling by stimulating stem cells and fibroblasts in the skin does restorative work in the best possible way. Given the fact that in skin- deep varicose, the faulty veins are at the skin surface, 20 weeks use of micronee- dling stimulates the vascular and skin tissues and reduces complications of varicose veins and consequently results in its improvement. The results showed that the use of microneedling can be a safe and effective treatment in reducing pain in patients with varicose veins in lower limbs. The findings showed that exercise in water could improve varicose. Since exercise, especially exercises in water, can be one of the factors affecting medical condition, and considering that changes in pain intensity and life quality scores depend on the type of physical activity, number of hours and of exercise sessions, intensity and duration of exercise, doctors and athletic trainers are suggested that while designing exercises consider special measures for active recreation programs.

\section{REFERENCES}

Carr, S. C. (2006). Current management of varicose veins. Clinical Obstetrics and Gynecology, 49(2), 414-426.

Chung, C. Y., McCray, W. H., Dhaliwal, S., Haywood, T., Black, M., Liu, J.-B., \&t Miller, L. S. (2000). Three-dimensional esophageal varix model quantification of variceal volume by highresolution endoluminal US. Gastrointestinal Endoscopy, 52(1), 87-91.

Diehm, C., \&t Diehm, N. (2002). Kneipp hydrotherapy, sclerotherapy, crossectomy. What really helps in varicose veins and spider veins? MMW Fortschritte Der Medizin, 144(35-36), 22-27.

Ernst, E., Saradeth, T., \&t Resch, K. L. (1992). Hydrotherapy for varicose veins: a randomized, controlled trial. Phlebology, 7(4), 154-157. 
Ghaffari, S., Ahmadi, F., Nabavi, S. M., Memarian, R., \& Kazemnejad, A. (2008). The effect of progressive muscle relaxation technique daily living activities in patients with multiple sclerosis. J Rehabilitation, 2(30), 73-80.

Gloviczki P, \& Yao JST. (2001). Handbook of Venous Disorders: Guidelines of the American Venous Forum. London, UK:Chapman and Hall Medical.

Goldman, M. P. (2002). Treatment of Varicose and Telangiectatic Leg Veins: Double-Blind Prospective Comparative Trial Between Aethoxyskerol and Sotradecol. Dermatologic Surgery, 28(1), 52-55.

Harrie, R. P., \&t Kendall, C. J. (2014). Case Study 137 Orbital Varix. In Clinical Ophthalmic Echography (pp. 315-315). Springer. Retrieved from http://link.springer.com/chapter/10. 1007/978-1-4614-7082-3_137
Mancini Jr, S., Piccinetti, A., Nappi, G., Mancini, S., Caniato, A., \& Coccheri, S. (2003). Clinical, functional and quality of life changes after balneokinesis with sulphurous water in patients with varicose veins. VASA. Zeitschrift Fur Gefasskrankheiten, 32(1), 26-30.

Stiegmann, G. V., Sun, J. H., \&t Hammond, W. S. (1988). Results of experimental endoscopic esophageal varix ligation. The American Surgeon, 54(2), 105-108.

Van Stiegmann, G., \&t Goff, J. S. (1988). Endoscopic esophageal varix ligation: preliminary clinical experience. Gastrointestinal Endoscopy, 34(2), 113-117.

Yaser A, \&t Sadeghi H. (2012). The effect of a water exercise program on static and dynamic balance in elder women. Soci Behavior Sci, 2220-2224. 